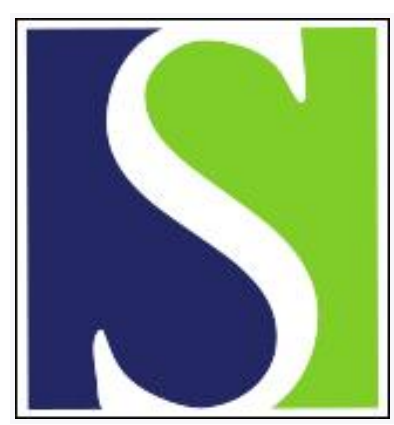

Scand J Work Environ Health 1988;14(5):306-311

https://doi.org/10.5271/sjweh.1915

Issue date: Oct 1988

Respiratory symptoms and pathophysiological effects of occupational exposure to formaldehyde and wood dust. by Holmstrom M, Wilhelmsson B

Affiliation: Department of Otolaryngology, Huddinge Hospital, Karolinska Institute, Sweden.

This article in PubMed: www.ncbi.nlm.nih.gov/pubmed/3201190

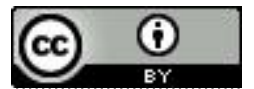




\title{
Respiratory symptoms and pathophysiological effects of occupational exposure to formaldehyde and wood dust
}

\author{
by Mats Holmström, MD, Bo Wilhelmsson, $\mathrm{MD}^{1}$
}

\begin{abstract}
HOLMSTRÖM M, WILHELMSSON B. Respiratory symptoms and pathophysiological effects of occupational exposure to formaldehyde and wood dust. Scand J Work Environ Health 14 (1988) 306-311. The hazards of exposure to formaldehyde have been widely discussed in recent years on account of the health complaints of exposed persons. Both domestic and occupational exposure to formaldehyde is common. In the present study the effects of formaldehyde alone and in combination with wood dust, another nasal irritant, on the upper and lower respiratory tract have been investigated. The effects were correlated with the duration and degree of exposure. Discomfort from both the upper and lower airways was more frequent in the exposed group than in the unexposed group. Nasal obstruction among the exposed subjects in general could not be detected by rhinomanometric measurements, but, for the group exposed to formaldehyde alone and with a history of nasal blocking, there was significant nasal mucosal swelling. The nasal mucociliary clearance was significantly delayed, and the sense of smell was significantly reduced in the exposed groups when they were compared with the referents. Spirometry showed a significantly decreased forced vital capacity in the exposed groups. There were no signs in this investigation that duration of exposure or level of exposure to formaldehyde would have any influence on the severity of symptoms or the impairment of physiological conditions.
\end{abstract}

Key terms: nasal irritants, respiratory physiology.

Formaldehyde is a common substance in different occupational environments, for example, in the chemical, furniture, wood, textile, and paper industries. It is also released in the general environment from, for example, building material, cigarette smoke, and perfume (18).

Formaldehyde is a highly reactive gas and is readily soluble in water. During nasal inhalation most of it is absorbed in the nose, and only a minimal amount reaches the lower airways (4).

The lowest concentration of formaldehyde that is detectable from its odor has been calculated to be $0.05 \mathrm{mg} / \mathrm{m}^{3}$ (13). It has also been found that $50 \%$ of a test group can detect $0.21 \mathrm{mg} / \mathrm{m}^{3}$. The eyes of human subjects can react with irritation to as little formaldehyde as $0.012 \mathrm{mg} / \mathrm{m}^{3}$ (16). Adaptation to formaldehyde takes place after long-term exposure (5).

Formaldehyde is an irritant to mucous membranes in the upper respiratory airways and conjunctiva. In a 5-h study, Andersen \& Mölhave (5) found no discomfort with formaldehyde levels of up to $0.5 \mathrm{mg} / \mathrm{m}^{3}$. With higher doses they found dose-related symptoms such as conjunctival irritation and dryness in the nose and throat. With high levels of exposure $\left(6-38 \mathrm{mg} / \mathrm{m}^{3}\right)$ irritation also occurs in lower airways (18).

The effects of long-term exposure on physiological variables have not been well investigated. Regarding

1 Department of Otolaryngology, Huddinge Hospital, Karolinska Institute, Sweden.

Reprint requests to: Dr M Holmström, Department of Otolaryngology, Huddinge Hospital, S-141 86 Huddinge, Sweden. the upper respiratory tract, very little is known. However, Schoenberg \& Mitchell (15) reported pulmonary obstruction after long-term exposure.

Numerous health complaints have been reported by occupants of homes insulated with material containing formaldehyde $(7,9)$. The concentrations of formaldehyde in such homes can reach $0.1 \mathrm{mg} / \mathrm{m}^{3}$ or more, and in mobile homes concentrations of more than $1 \mathrm{mg} / \mathrm{m}^{3}$ have been reported.

We had previously found that wood dust is a cause of health complaints among occupationally exposed men (17). Combined exposure to both formaldehyde and wood dust is common in the furniture industry, where formaldehyde is released from particle board. Since both compounds are hazardous to the nose, it was considered of interest to investigate whether exposure to a combination of formaldehyde and wood dust has an additive adverse effect. It could be presumed that wood dust would act as a carrier of absorbed formaldehyde to the lower airways.

The objective of the present study was thus to examine the effects of long-term exposure to formaldehyde alone and in combination with exposure to wood dust with respect to symptoms and physiological variables in the upper and lower airways.

\section{Subjects}

In collaboration with the Swedish National Board of Occupational Safety and Health, three test groups were chosen to participate in a cross-sectional study. One group consisted of 70 persons from a chemical plant 
where formaldehyde and products based on formaldehyde were produced (resins and impregnation of paper for laminate production). This group was exposed almost exclusively to formaldehyde as the only nasal irritant. The exposure levels were mainly between 0.05 and $0.5 \mathrm{mg} / \mathrm{m}^{3}$ [mean value in 1985: 0.26 (SD 0.17) $\left.\mathrm{mg} / \mathrm{m}^{3}\right]$. For the group of workers impregnating paper $(\mathrm{N}=31)$ dust concentrations of up to $1 \mathrm{mg} / \mathrm{m}^{3}$ have been measured close to the machines. At other workstations the dust levels were much lower.

A second group of 100 persons was exposed to both wood dust and formaldehyde during work with glued wood in the production of furniture. Their mean levels of exposure were mainly $0.2-0.3 \mathrm{mg} / \mathrm{m}^{3}$ [mean value in 1985: $0.25(\mathrm{SD} 0.05) \mathrm{mg} / \mathrm{m}^{3}$ ] for formaldehyde and $1-2 \mathrm{mg} / \mathrm{m}^{3}$ [mean value in 1985: 1.65 (SD 1.06) $\mathrm{mg} / \mathrm{m}^{3}$ ] for wood dust.

The third group was a reference group of 36 persons, most of whom were clerks in the local government of the same village as the furniture workers. The mean exposure to formaldehyde in their office over a year was $0.09 \mathrm{mg} / \mathrm{m}^{3}$.

None of the participants of any of the three groups was occupationally exposed to solvents. Exposure to other chemicals such as phenol, ammonia, epichlorhydrin, methanol, and ethanol have repeatedly been measured without any values over $1 \%$ of the occupational exposure limit. None of the subjects refused to participate in the investigation. Six participants were excluded from the physiological tests because of upper airway infection.

The mean exposure of every participant to both formaldehyde and wood dust was estimated for every year since the beginning of their employment. This estimation was made possible by numerous current and prior measurements of the exposure levels. In 1985 we performed several measurements of the exposure level at all different workstations using personal sampling equipment placed in the breathing zone of the worker. Samples were taken for the analysis of formaldehyde, total dust, and respirable dust. The sampling lasted $1-2 \mathrm{~h}$ for formaldehyde, $4 \mathrm{~h}$ for total dust, and $8 \mathrm{~h}$ for respirable dust. In the chemical plant several formaldehyde concentration measurements were made between 1979 and 1984. The exposure levels before 1979 were assumed to be the same as in 1979. In the furniture plants the exposure levels could only be evaluated reliably for 1985 . Exposure prior to 1985 was thus assumed to be the same as that of 1985 in the furniture plants. A sum of the dose-years was thus obtained for each participant (ie, annual exposure to formaldehyde of $0.5,0.3$, and $0.3 \mathrm{mg} / \mathrm{m}^{3}$ in three years gives a doseyear of 1.1).

There were no significant differences in tobacco use between the groups. The mean duration of occupational exposure was 10.4 (SD 7.3, range $1-36$ ) years for the formaldehyde group, 16.6 (SD 11.3, range $1-45)$ years for the wood dust-formaldehyde group, and 11.4 (SD 5.4, range 4-18) years for the reference group. The mean age of the subjects was 36.9 years for the formaldehyde group, 40.5 years for the wood dust-formaldehyde group, and 39.9 years for the reference group. In the formaldehyde group $87 \%$ were men. The corresponding figures for the wood dustformaldehyde group and the reference group were 93 and $56 \%$, respectively.

\section{Methods}

The examination of each participant was made on three different days since the different methods might influence each other. The test for mucociliary clearance and the spirometry was made one day, rhinomanometry on another, and the olfactory test on a third. The participants with current upper airway infections were excluded from the physiological tests of the upper airways. All the examinations took place in April or late September in the subjects' workplaces, indoors with ordinary temperature and humidity.

A questionnaire was distributed a few days before the medical examination. The answers to the questions about work conditions and symptoms were thoroughly checked by one of the authors in connection with this examination.

The medical examination focused on the ear, nose, and throat. The rhinomanometry was carried out as described by Kumlien \& Schiratzki (12), with recording of the pressure drop and airflow rate in the nose during inhalation. Duplicate measurements with anterior rhinomanometry were made both before and after decongestion (with an oxymetazoline spray). Calculations of the curve of the nasal resistance were made according to the method of Broms et al (8). The nasal volume flow rate $\left(\mathrm{V}_{2}\right)$ was used for the statistical calculations.

The mucociliary activity was tested with a spot of Cardiogreen ${ }^{\circledR}$ Sterile Indocyanine Green, (from Hynson, Westcott and Dunning Products, Maryland, United States) placed on both inferior turbinates $1 \mathrm{~cm}$ posterior to the anterior border of the turbinate. The time taken for the spot to reach the rhinopharynx was measured. A transport time of more than $20 \mathrm{~min}$ on one or both sides was considered pathological.

An olfactory test was performed with a series of binary pyridine dilution steps (from Olfacto Labs, ElCerrito, United States) as described by Amoore \& Ollman (3). For each participant the lowest concentration of pyridine that could be reliably detected was estimated. The normal range of sensitivity (found in $96 \%$ of healthy persons aged $20-60$ years) extends from step 14 to step 21 . A sensitivity below step 14 is regarded as hyposmia.

The spirometry was carried out with a vitalograph (KIFA $^{\text {reg }}$ serial no 980230 made by Vitalograph Ltd, England). At least three efforts were recorded by each subject, and the best one was used for all the calculations. All the individual values were compared with 
the expected normal values (based on age, sex, smoking habits, height, and weight) (6). Ex-smokers were classified as smokers if less than two years had elapsed since they stopped smoking; otherwise they were considered nonsmokers. Forced vital capacity (FVC) and FEV $\%$ [ $(100 \times$ the forced expiratory volume in $1 \mathrm{~s}) / \mathrm{FVC}]$ were measured.

A chi-square test based on a binomial model or Fisher's exact test was used to analyze the responses to the questionnaire. The physiological variables were analyzed statistically with a two-tailed t-test except for the evaluation of mucociliary clearance, for which the chisquare test was used. The differences were classified as significant if the P-value was $<0.05$.

\section{Results}

From the questionnaire it was found that nasal discomfort occurred for $64 \%$ of the group exposed to formaldehyde, $53 \%$ of the wood dust-formaldehyde group, and $25 \%$ of the reference group (table 1). The differences between the exposed groups and the reference group were statistically significant $(\mathrm{P}<0.001$ for the formaldehyde group and $\mathrm{P}<0.01$ for the wood dust-formaldehyde group). Symptoms from the lower airways, ie, trachea and bronchi, were also more frequently found in the exposed groups - in $44 \%$ $(\mathrm{P}<0.01)$ of the formaldehyde group and $39 \%$ $(\mathrm{P}<0.05)$ of the group exposed to wood dust and formaldehyde, compared with $14 \%$ of the reference group. More specific symptoms, such as nasal obstruc- tion and nasal watery discharge, were also more frequent in the exposed groups $(\mathrm{P}<0.05)$. Other findings, such as eye symptoms and headache, were significantly more frequent in the formaldehyde group than in the reference group, but the difference between the wood dust-formaldehyde group and the reference group was not significant (table 1).

No symptoms were more common in the reference group than in the other two groups. Most of the symptoms among the exposed groups were connected with the groups' occupation (table 1). In the reference group only one person had symptoms during workhours (allergy to a carpet), and therefore no statistical comparisons were made with the reference group in this respect.

The symptoms had an earlier onset in the formaldehyde group than in the wood dust-formaldehyde group. Nasal symptoms started 4.3 years after first employment in the former and 9.9 years after first employment in the latter. For symptoms of the lower airways, the latency periods were 3.0 and 12.4 years, respectively. A majority of workers $(55-82 \%)$ in both the exposed groups considered the symptoms to have remained unchanged in recent years. Among the exposed subjects, $23-29 \%$ reported that their symptoms had increased in severity in recent years, and $5-15 \%$ stated that they had become less pronounced.

Symptoms related to the work situation decreased, as expected, during free time. In about $60 \%$ of both exposed groups the symptoms improved during weekends (table 2). During vacation however, there was improvement in significantly more persons in the

Table 1. Workers exposed to formaldehyde alone and to both wood dust and formaldehyde and the reference group according to experienced symptoms.

\begin{tabular}{|c|c|c|c|c|c|c|c|c|c|c|c|c|}
\hline \multirow{3}{*}{ Symptom } & \multicolumn{6}{|c|}{ Total frequency of symptoms } & \multicolumn{6}{|c|}{ Frequency of work-related symptoms } \\
\hline & \multicolumn{2}{|c|}{$\begin{array}{c}\text { Formaldehyde } \\
\text { group } \\
(\mathrm{N}=70)\end{array}$} & \multicolumn{2}{|c|}{$\begin{array}{c}\text { Wood dust- } \\
\text { formaldehyde } \\
\text { group } \\
(\mathrm{N}=100)\end{array}$} & \multicolumn{2}{|c|}{$\begin{array}{c}\text { Reference } \\
\text { group } \\
(\mathbf{N}=36)\end{array}$} & \multicolumn{2}{|c|}{$\begin{array}{l}\text { Formalde- } \\
\text { hyde group } \\
(\mathbf{N}=70)\end{array}$} & \multicolumn{2}{|c|}{$\begin{array}{l}\text { Wood dust- } \\
\text { formalde- } \\
\text { hyde group } \\
(\mathrm{N}=100)\end{array}$} & \multicolumn{2}{|c|}{$\begin{array}{c}\text { Reference } \\
\text { group } \\
(\mathrm{N}=36)\end{array}$} \\
\hline & $\mathrm{N}$ & $\%$ & $N$ & $\%$ & $\mathrm{~N}$ & $\%$ & $N$ & $\%$ & $\mathrm{~N}$ & $\%$ & $\mathrm{~N}$ & $\%$ \\
\hline Nasal discomfort & 45 & $64^{* * *}$ & 53 & $53^{* *}$ & 9 & 25 & 36 & 51 & 44 & 44 & 1 & 3 \\
\hline Eye discomfort & 17 & $24^{*}$ & 21 & 21 & 2 & 6 & 14 & 20 & 16 & 16 & - & . \\
\hline $\begin{array}{l}\text { Deeper airway dis- } \\
\text { comfort }\end{array}$ & 31 & $44^{* *}$ & 39 & $39^{*}$ & 5 & 14 & 22 & 31 & 31 & 31 & - & . \\
\hline Frequent headache & 17 & $24^{*}$ & 17 & 17 & 2 & 6 & 13 & 18 & 8 & 8 & - & . \\
\hline
\end{tabular}

${ }^{*} \mathrm{P}<0.05,{ }^{* *} \mathrm{P}<0.01,{ }^{* * *} \mathrm{P}<0.001$.

Table 2. Relief from symptoms during weekends and vacation among workers with symptoms of the upper and lower airways. (NS = not significant)

\begin{tabular}{|c|c|c|c|c|c|c|c|}
\hline & \multicolumn{3}{|c|}{ Formaldehyde group } & \multicolumn{3}{|c|}{ Wood dust-formaldehyde group } & \multirow{3}{*}{$\begin{array}{c}\text { Statistics } \\
\text { (Chi-square } \\
\text { test) }\end{array}$} \\
\hline & \multirow{2}{*}{$\begin{array}{c}\text { Number with } \\
\text { symptoms on } \\
\text { workdays }\end{array}$} & \multicolumn{2}{|c|}{$\begin{array}{l}\text { Persons } \\
\text { relieved of } \\
\text { symptoms }\end{array}$} & \multirow{2}{*}{$\begin{array}{c}\text { Number with } \\
\text { symptoms on } \\
\text { workdays }\end{array}$} & \multicolumn{2}{|c|}{$\begin{array}{l}\text { Persons } \\
\text { relieved of } \\
\text { symptoms }\end{array}$} & \\
\hline & & $N$ & $\%$ & & $N$ & $\%$ & \\
\hline $\begin{array}{l}\text { Weekends } \\
\text { Vacation month }\end{array}$ & $\begin{array}{l}43 \\
43\end{array}$ & $\begin{array}{l}26 \\
29\end{array}$ & $\begin{array}{l}61 \\
67\end{array}$ & $\begin{array}{l}56 \\
56\end{array}$ & $\begin{array}{l}36 \\
49\end{array}$ & $\begin{array}{l}64 \\
88\end{array}$ & $\begin{array}{c}\text { NS } \\
P=0.0170\end{array}$ \\
\hline
\end{tabular}


wood dust-formaldehyde group ( $88 \%$ ) than in the formaldehyde group $(67 \%)$. This difference was significant $(\mathrm{P}=0.017)$.

We divided all the subjects into three groups on the basis of their current level of exposure to formaldehyde to see whether the frequency of symptoms was correlated with the exposure levels. One group was exposed to less than $0.24 \mathrm{mg} / \mathrm{m}^{3}(\mathrm{~N}=74$, with 29 of the 74 from the formaldehyde group), another to $0.25-0.49 \mathrm{mg} / \mathrm{m}^{3}(\mathrm{~N}=74$, with 23 of the 74 from the formaldehyde group), and a third to $0.5 \mathrm{mg} / \mathrm{m}^{3}$ or more $(\mathrm{N}=18$, all from the formaldehyde group). However, the frequency of airway symptoms or headache did not differ with different exposure levels in either the formaldehyde or the wood dust-formaldehyde group.

Rhinomanometry showed more pronounced mucosal swelling in both exposed groups than in the reference group. The greatest degree of swelling was found in the formaldehyde group, for which the difference in nasal resistance $\left(\mathrm{V}_{2}\right.$ value) before and after decongestion was 10.2, compared with 7.87 for the wood dust-formaldehyde group and 6.5 for the reference group. However, the differences between the exposed groups and the reference group were not statistically significant $(T=1.76$ for the formaldehyde group and 1.11 for the wood dust-formaldehyde group). There was no evidence that the degree of mucosal swelling increased after a long period of employment. Nor did high cumulative exposure to formaldehyde (5.0 or more dose-years) increase the mucosal swelling more than moderate (1.5-4.9 dose-years) or low ( $<1.5$ doseyears) cumulative exposure.

To investigate whether a history of a nasal obstruction was correlated with the rhinomanometric value, we compared the nasal resistance values before and after decongestion between workers with and without such a history in each group. In the formaldehyde group the difference in nasal resistance $\left(\Delta V_{2}\right)$ was significantly greater among the workers with a history of nasal obstruction than among those without $(P<0.05)$, an indication of nasal mucosal edema in those with symptoms. In the wood dust-formaldehyde group and in the reference group the corresponding difference was not significant.

The number of persons with impaired mucociliary clearance in the nose differed between each of the exposed groups and the reference group. In the formaldehyde group 14 out of 69 subjects $(20 \%)$ had pathologically slow nasal clearance, and in the wood dustformaldehyde group this number was 14 of $95(15 \%)$. In the reference group only one subject out of $36(3 \%)$ had a pathological clearance time. The results were significant $(\mathrm{P}<0.05)$ for the formaldehyde group but not for the wood dust-formaldehyde group in comparison with the reference group.

Based on the mean values in the olfactory test, a significant decrease in the sense of smell $(\mathrm{P}<0.01)$ was found in both exposed groups when they were com- pared with the reference group. The mean value was 14.2 for both the formaldehyde group and the wood dust-formaldehyde group and $\mathbf{1 5 . 6}$ for the reference group. There was thus no difference in the sense of smell between the formaldehyde and formaldehydewood dust groups. When the workers in the formaldehyde group were divided into one subgroup exposed to a mean formaldehyde concentration of less than $0.5 \mathrm{mg} / \mathrm{m}^{3}$ during the last year and another exposed to more than $0.5 \mathrm{mg} / \mathrm{m}^{3}$, no difference in the sense of smell was found, the mean values in the olfactory test being 14.2 and 14.1 , respectively. When the subjects' own estimations of their sense of smell were compared with the results of the olfactory test, a significant correlation was found for the formaldehyde group $(\mathrm{P}<0.05)$; thus nine subjects with subjective hyposmia had a mean value of 12.0 for the test, while the mean value for those without hyposmia was 14.48 . In the wood dust-formaldehyde group there was no such correlation. In both exposed groups there was a slight decrease in olfactory sense with increasing age. There was no significant deterioration in the sense of smell with increasing duration of employment or in relation to the cumulative dose of formaldehyde. Neither did smokers have a lower sense of smell than nonsmokers.

To estimate whether nasal obstruction could explain an impaired sense of smell, we compared workers grouped according to degree of mucosal swelling (ie, difference between the pre- and postdecongestion $\mathrm{V}_{2}$ ) regarding their olfactory test results. The mean value in the pyridine test was compared between the workers with mucosal swelling above and below the group mean of the mucosal swelling. No difference in the pyridine test result was found either for the exposed groups or the reference group between subjects with different degrees of mucosal swelling.

In the results of the spirometric tests the mean FVC of both the exposed groups was significantly lower $(\mathrm{P}<0.001)$ than the expected value (table 3$)$. In the formaldehyde group this difference in FVC was $0.577 \mathrm{I}$ and in the wood dust-formaldehyde group it was $0.664 \mathrm{l}$. In the reference group the FVC did not differ significantly from the expected value. To analyze the relation between the duration of exposure and the decrease in vital capacity, we divided the subjects of the three groups into subgroups based on exposure time. There were no signs of increasing restrictivity after longer employment than five years. Neither was there any correlation between degree of decrease in FVC and cumulated formaldehyde dose. No correlation was found between the reduction in FVC and smoking habits. Thus the differences from the expected FVC values were not more pronounced among the smokers than among the nonsmokers or ex-smokers.

The mean FEV \% was 80.8 for the formaldehyde group (expected value $80.6 \%$ ). In the wood dust-formaldehyde group the mean FEV $\%$ was 78.3 , compared with an expected value of $79.5 \%$, and in the refer- 
Table 3. Results of the pulmonary function tests in the group exposed to formaldehyde, that exposed to both wood dust and formaldehyde, and the reference group. In the statistical anal ysis (paired t-test) comparisons were made between the observed and expected values.

\begin{tabular}{lccc}
\hline & $\begin{array}{c}\text { Formaldehyde } \\
\text { group } \\
(\mathbf{N}=70)\end{array}$ & $\begin{array}{c}\text { Wood dust- } \\
\text { formaldehyde } \\
\text { group } \\
(\mathbf{N}=98)\end{array}$ & $\begin{array}{c}\text { Reference } \\
\text { group } \\
(\mathbf{N}=36)\end{array}$ \\
\cline { 2 - 4 } & & & \\
$\begin{array}{l}\text { Forced vital } \\
\text { capacity }\end{array}$ & & & \\
Observed & $4.979^{\star \star *}$ & $4.929^{* \star *}$ & 4.539 \\
Expected & 5.556 & 5.593 & 4.718 \\
FEV \% & & & \\
Observed & 80.8 & 78.3 & 81.4 \\
Expected & 80.6 & 79.5 & 80.7 \\
\hline
\end{tabular}

a $\mathrm{FEV} \%=(100 \times$ forced expiratory volume in $1 \mathrm{~s}) /$ forced vital capacity. $* * * P<0.001$.

ence group the corresponding values were 81.4 and $80.7 \%$ (table 3 ).

\section{Discussion}

The observed formaldehyde concentrations $(0.05-0.5$ $\mathrm{mg} / \mathrm{m}^{3}$ ) are representive of Swedish industry of today. The values are however well below the present Swedish occupational exposure limit $\left(1 \mathrm{mg} / \mathrm{m}^{3}\right)$ and can also be measured in certain nonindustrial environments.

In this study a high incidence of work-related symptoms was found among the exposed workers. Symptoms from the upper airways were especially pronounced, but symptoms from the lower airways were also more frequent than in the reference group. The symptoms were mainly of the same type as those described earlier for formaldehyde exposure (5). They seemed to be more pronounced in the formaldehyde than in the wood dust-formaldehyde group. This finding might have been due to the fact that the formaldehyde exposure levels were higher in the former group than in the latter. When, however, the formaldehyde group was divided into subgroups according to degree of exposure to formaldehyde, the symptoms were not found to be significantly more pronounced in the group exposed to more than $0.5 \mathrm{mg} / \mathrm{m}^{3}$ than that exposed to a lower level.

It was found on the basis of several parameters (rhinomanometry, spirometry, olfactory test) that the workers' symptoms did not become more severe after long-term exposure. On the other hand, the workers did not seem to develop tolerance to the formaldehyde exposure with time, and a majority of the exposed individuals reported that their symptoms had remained unchanged in recent years.

Even though there is a risk of questionnaire results being biased, a very strong correlation was found between symptoms and work, as reported by $72 \%$ of the formaldehyde group, $79 \%$ of the wood dust-formaldehyde group, and $6 \%$ (one person) of the refer- ents. It is probable that the workers who had the most pronounced symptoms left exposed work for a new job.

Symptoms persisted longer during free time in the formaldehyde group than in the group exposed to wood dust and formaldehyde. The reason might be the more severe symptoms in the former group and the fact that they also had more pronounced histological changes than the reference group (11).

One theory pertaining to the preceding finding is that formaldehyde primarily causes symptoms through action on the epithelial structures, and wood dust through mucostasis. In another study (17), Wilhelmsson \& Drettner found a higher frequency of impaired mucociliary activity among workers exposed to higher levels of wood dust than was noted in the present study. The role of impaired mucociliary activity is obvious. The worker might notice it as nasal obstruction or discharge. Ciliary stasis also gives the dust or chemical substances more time to act on the mucosa.

Impairment of nasal function was found in the formaldehyde group for all the physiological tests of this function, ie, the olfactory test, the test of mucociliary clearance, and the rhinomanometry (for the last test statistically significant only for those persons with symptoms of nasal obstruction). The olfactory function was also decreased in the wood dustformaldehyde group when it was compared with the reference group $(P<0.01)$, but nasal obstruction and the decrease in mucociliary clearance were not so pronounced as in the formaldehyde group. The mechanism of depressed olfactory function is obscure. It was not found that mucosal blockage could explain the decrease in the sense of smell. A possible explanation is a direct toxic effect of formaldehyde on the olfactory epithelium.

Statistically, no evidence was obtained that workers exposed to formaldehyde had more nasal obstruction in general, as measured by rhinomanometry, than the reference group - although there was a large difference regarding the reported history of nasal blockage. However, the workers with a history of nasal obstruction in the formaldehyde group showed a significant decrease in nasal resistance $\left(\Delta \mathrm{V}_{2}\right)$ after decongestion, a finding indicating nasal mucosal edema. It is conceivable that the exposed workers had nasal obstruction that was not reversed by oxymetazoline spray.

In our study there was no statistically significant decrease in the FEV \% after long-term exposure to formaldehyde. A significant increase in pulmonary restrictiveness was observed, as reflected by a decrease in FVC in comparison with the expected value both among the workers exposed to formaldehyde and among those exposed to wood dust-formaldehyde. However, it could not be excluded that there is hidden pulmonary obstructivity in these cases that is not possible to determine with a vitalograph. We did not perform any test of reversibility in pulmonary resistance in this study. 
It has been reported that rats exposed to formaldehyde $5 \mathrm{~d}$ a week for five weeks did not show physiological changes in the deeper airways (14). During short-term exposure of man, Alexandersson et al (2) found a reduction in forced expiratory volume in $1 \mathrm{~s}$ after a day of work, and this finding suggests the possibility of bronchoconstriction. Schoenberg \& Mitchell (15) observed that workers developed chronic airway obstruction after long-term exposure to phenolformaldehyde resins. Alexandersson et al (1) has shown that in nonsmokers there is a significant restitution of pulmonary obstruction and restrictivity after four weeks' rest from work among formaldehyde-exposed workers.

Most formaldehyde inhaled through the nose is absorbed in the nose, and only a very small amount reaches the deeper airways (4). In the presence of nasal blockage, with mouth breathing, more formaldehyde can probably reach the lungs. There is also a possibility that formaldehyde absorbed on particles, ie, wood dust, might reach deeper airways more easily than gaseous formaldehyde, especially if the mucociliary system in the nose is defective. No signs of a hematogenous distribution of formaldehyde to distant organs have been found either in man or in rat (10). Even with high exposure levels, no rise in the blood concentration of formaldehyde has been observed.

In the presence of different substances that are noxious to the lungs, tobacco smoking increases the risk of disease. However, we did not find that more pronounced restrictiveness developed in smokers than in nonsmokers.

The pulmonary restrictiveness in the wood dustformaldehyde group was just as pronounced as in the formaldehyde group, although the formaldehyde level in the former group was lower. The reason for this finding might be that, in the former group, the formaldehyde was absorbed by wood dust particles. In a previous study (17) we found, however, that workers exposed to wood dust alone also developed restrictiveness. But in that study the dosage of wood dust was higher.

\section{Acknowledgments}

We thank Mr G Rosén and his staff at the Swedish National Board of Occupational Safety and Health for the exposure analysis.

This investigation was supported financially by the Swedish Work Environment Fund (project no 81-0313).

\section{References}

1. Alexandersson R, Andersson I-M, Hedenstierna G, Rosén G, Randma E. Lungpåverkan hos limmare i träindustrin [Pulmonary effects in glueing workers in the wood working industry]. Arbetarskyddsverket, Stockholm 1987. (Arbete och hälsa 1987: 14).

2. Alexandersson R, Kolmodin-Hedman B, Hedenstierna G. Exposure to formaldehyde: Effects on pulmonary function. Arch Environ Health 37 (1982) 279-283.

3. Amoore JE, Ollman BG. Practical test kits for quantitatively evaluating the sense of smell. Rhinology 21 (1983) 49-54.

4. Andersen I, Proctor DF. The rate and effects of inhaled materials. In: Proctor DF, Andersen I, ed. The nose, upper airway physiology and the atmospheric environment. Elsevier Biomedical Press, Amsterdam 1982, pp $423-427$.

5. Andersson I, Mölhave L. Controlled human studies with formaldehyde. In: Gibson JE, ed. Formaldehyde toxicity. Hemisphere Publishing Corporation, Washington, DC 1983, pp 154-165.

6. Berglund E, Birath G, Bjure J, Kjellmer J, Sandqvist L, Söderholm B. Spirometric studies in normal subjects. Acta Med Scand 173 (1963) 185-198.

7. Bracken MJ, Leasa DJ, Morgan WKC. Exposure to formaldehyde: Relationship to respiratory symptoms and function. Can J Publ Health 76 (1985) 312-316.

8. Broms P, Jonson B, Lamm CJ. Rhinomanometry: A system for numerical description of the nasal airway resistance. Acta Oto Laryngol 94 (1982) 157-168.

9. Dally KA, Hamrahan LP, Woodbury MA, Kanarek MS. Formaldehyde exposure in nonoccupational environments. Arch Environ Health 36 (1981) 277-284.

10. Heck H d'A, Casanova-Schmitz M. The relevance of disposition studies to the toxicology of formaldehyde. CIIT Act 4 (1984) 2-5.

11. Holmström M, Wilhelmsson B, Hellqvist H, Rosén G. Histological effects of formaldehyde alone and in combination with wood dust on the nasal mucosa in occupationally exposed persons. Acta Oto Laryngol (in press).

12. Kumlien J, Schiratzki H. Methodological aspects of rhinomanometry. Rhinology 17 (1979) 107-114.

13. Pettersson S, Rehn T. Lukttröskelbestämning av formaldehyd [Determination of the odor threshold for formaldehyde]. Hygien och miljö 10 (1977) 35-37.

14. Saldiva PHN, Caldeira MPR, Massad E, Calheiros DF, Cardoso LMN, Böhm GM, Saldiva CD. Effects of formaldehyde and acetaldehyde inhalation on rat pulmonary mechanics. J Appl Toxicol 5 (1985) 288-292.

15. Schoenberg JB, Mitchell CA. Airway disease caused by phenolic (phenol-formaldehyde) exposure. Arch Environ Health 30 (1975) 574-577.

16. Schuch EA, Stephens ER, Middleton JT. Eye irritation response at low concentrations of irritants. Arch Environ Health 13 (1966) 570-575.

17. Wilhelmsson B, Drettner B. Nasal problems in wood furniture workers. Acta Oto Laryngol 98 (1984) 548-555.

18. . . Report on the consensus workshop on formaldehyde. Environ Health Perspect 58 (1984) 323-381.

Received for publication: 13 January 1988 